\title{
Can total laparoscopic hysterectomy replace total abdominal hysterectomy? A 5-year prospective cohort study of a single surgeon's experience in an unselected population
}

\author{
D. Ghosh • P. Wipplinger - D. L. Byrne
}

Received: 4 April 2012 / Accepted: 28 June 2012 /Published online: 22 July 2012

(C) Springer-Verlag 2012

\begin{abstract}
Total laparoscopic hysterectomy (TLH) has wellestablished advantages over total abdominal hysterectomy in benign gynaecology. We evaluated the outcome of a single surgeon who offered TLH as the default surgical procedure for all non-vaginal hysterectomies in an unselected gynaecology clinic population. TLH was offered as the default method of hysterectomy for patients from September 1, 2006, and data were collected up to August 31, 2011. Data were collected on indication for surgery, previous surgery, pelvic pathology, intraoperative findings, uterine weight and/or size, complications and conversion to open hysterectomy. Primary outcomes were the proportion of hysterectomies performed laparoscopically, complications and conversion rates. A total of 173 hysterectomies were performed; 18 (10\%) were total abdominal hysterectomy (TAH), 17 (10 \%) were vaginal hysterectomies (VH), and $138(80 \%)$ were TLH. TLH rates increased from $51 \%$ in year 1 to $100 \%$ in years 3, 4 and 5 for women that elected for laparoscopic approach. The median uterine weight for TLH increased each year from $110 \mathrm{~g}$ (range 58-209 g) in year 1 to $240 \mathrm{~g}$ (range 70-584 g) in year 5. All patients were deemed suitable for laparoscopic approach irrespective of the uterine size and comorbidities by year 3 with only a single conversion in year 4 . There were 11 major surgical complications: VH 0 (0 \%), TAH 1 (5.6 \%) and TLH 10 (7.2\%) and three $(2.2 \%)$ conversions to laparotomy. Once a surgeon's laparoscopic expertise plateaus, TLH can be offered to patients as the default procedure for non-vaginal hysterectomy in an unselected UK population with benign disease.
\end{abstract}

Keywords Learning curve $\cdot$ Total laparoscopic hysterectomy

D. Ghosh $\cdot$ P. Wipplinger $\cdot$ D. L. Byrne $(\bowtie)$

Department of Gynaecology, Royal Cornwall Hospital,

Truro TR1 3LJ Cornwall, UK

e-mail: dominic.byrne@rcht.cornwall.nhs.uk

\section{Background}

Since the first total laparoscopic hysterectomy (TLH) was described [1], there is increasing evidence that it provides advantages over vaginal hysterectomy ( $\mathrm{VH})$ [2] and total abdominal hysterectomy (TAH) in benign gynaecology [3]. The National Institute for Health and Clinical Excellence promotes the advantages of laparoscopic hysterectomy for early endometrial cancer [4] and supports its use as a choice for benign hysterectomy [5].

TLH has been shown in randomised trials to result in a reduction in postoperative pain and an enhanced recovery when compared to open hysterectomy $[3,6]$. It has also been shown that patients have a shorter hospital stay when compared with abdominal and vaginal hysterectomy [7]. Despite this evidence, laparotomy is currently the most common surgical route for hysterectomy [8].

Whilst the benefits for patients are proven, the technical and financial challenges of TLH have delayed its adoption into standard practice. TLH takes longer to perform [3] and carries higher equipment costs when compared to open hysterectomy [9]. Where direct and indirect costs of abdominal and laparoscopic hysterectomy were evaluated using combined data from controlled trials, shorter hospital stay was shown to compensate for the higher procedural costs of laparoscopic hysterectomy [10]. A cost comparison using a societal perspective model analysed hospital inpatient costs, equipment costs, lost wages and caregiver costs of robotic, laparoscopic and abdominal hysterectomy for endometrial cancer and predicted laparoscopy as the least expensive approach [11]. Further research to evaluate hysterectomy costs in benign gynaecology, including mapping the complete patient journey, is required where societal factors and economic benefits are likely to balance the cost in favour of TLH.

Laparoscopic hysterectomy is considered more difficult than abdominal hysterectomy [12]. The technical challenges 
of laparoscopic surgery may be daunting for a surgeon who is very competent at open hysterectomy, as it returns the surgeon to a novice status once again. Some surgeons relish the new challenges whilst others find it difficult to relearn and do not wish to change. The support and infrastructure to learn complex laparoscopic surgery is also variable and the service pressures of current roles may frustrate such development. The technical challenges of a laparoscopic approach include limited instrument mobility and positioning, as instruments are fixed at the port site. Laparoscopic surgery is visualised in two dimensions, so depth cannot be seen, it must be learned. These factors, accompanied by the altered ergonomics, increase the difficulty of a laparoscopic approach [13]. The learning curve for TLH has previously been studied and defined according to the number of procedures performed by assessing complication rates and the length of operating time in a novice and experienced laparoscopic surgeon. In the experienced surgeon, the learning curve reached a plateau at the first 10 cases [14]. The average duration of laparoscopic hysterectomy has been shown to be comparable to abdominal hysterectomy as experience is gained [15]. It should be expected that with increasing experience, surgeons would undertake more complex laparoscopic hysterectomies, which whilst expanding the applicability of the procedure, will conversely add to the operative time.

\section{Methods}

This study examines the 5-year outcome of a single surgeon with 25 years surgical experience of abdominal and vaginal hysterectomy who, after 12 years of preparatory training (comprising surgical training courses, personal mentoring and performing laparoscopically assisted vaginal hysterectomy, then TLH on selected patients), introduced TLH as the default method of non-vaginal hysterectomy from September 1, 2006.

We collected data on all hysterectomies, irrespective of route, performed by one surgeon over a 5-year period to determine what proportion was successfully carried out laparoscopically. As these data include all patients offered hysterectomy in one consultant general gynaecology clinic, it is a complete dataset and not subject to selection bias. Consequently, it will determine the true outcome if TLH is offered as the primary route for surgery. The cohort will also demonstrate any changes in selection criteria and case complexity as the surgeon's experience increases.

Patients were informed that TLH was a new procedure and early cases were told specifically how many procedures the surgeon had performed. All were told that conversion to an open procedure was a possibility and that they could elect for an open procedure from the outset. This cohort is a complete data set of the named surgeon's practice as all patients remained under his care irrespective of route of hysterectomy or indication for procedure. There was only one patient (in year 5) referred to another consultant for hysterectomy. This patient was listed for a TLH but requested an alternative surgeon as the procedure could be carried out sooner; in doing so, she accepted a TAH. So with the exception of this single patient, there is no selection bias in the population studied.

Outcome data were retrieved by a search of the Royal Cornwall Hospitals Trust theatre database for all patients undergoing hysterectomy between September 1, 2006 and August 31, 2011 (5-year complete data) under the care of one of the authors (DLB). Cases were cross-referenced with the surgeon's personal records to ensure all patients were included. The notes of all patients were collected and a standardised data set was recorded on a prepared pro forma.

The indication for surgery, any previous abdominal surgery and known pelvic pathology were recorded, along with the name of the listing surgeon, the operating surgeon and the patients named consultant. Intraoperative findings were recorded including size of uterus, adhesions, endometriosis or congenital abnormalities. Intraoperative and postoperative complications and conversion to laparotomy were recorded. The uterine weight and (or) size was recorded from the histopathology report. The reason for hysterectomy not being performed laparoscopically was also recorded.

Total laparoscopic hysterectomy was performed using a 10-mm zero degree laparoscope through the umbilicus with one lateral $5-\mathrm{mm}$ port on each side. An additional 10-mm port was placed suprapubically. The procedure was performed using a bipolar Maryland forceps (Olympus, Hamburg, Germany) and a Lotus ultrasonic scalpel (SRA Developments Ltd, Ashburton, UK). The pedicles were secured and divided in turn to include the adnexae as necessary. In complex endometriosis cases, the ureters were dissected as required. A colpotomy cup was used to prevent gas escaping when the vagina was opened. In the early procedures, this was a McCartney Tube (LiNA Medical UK Ltd, Cullompton, UK) and in later procedures, a Hohl uterine manipulator (Storz GmbH \&Co, Tuttlingen, Germany) incorporating a colpotomy cup was used. The vaginal vault was sutured laparoscopically with a continuous suture and intracorporeal knots. The suprapubic port site was closed with a deep suture. All wounds were then closed with absorbable skin sutures. In procedures with a large fibroid uterus, the laparoscope port was placed high in the abdomen and the umbilical port was used for instrumentation. In addition, in very large fibroid uterus cases, bilateral uterine artery occlusion was carried out at source at the start of the procedure. Large fibroid uteri were morcellated using a Rotocut morcellator (Storz GmbH \&Co, Tuttlingen, Germany) to facilitate removal. A urinary catheter was inserted 
at the onset of the procedures and removed the following morning. Patients were discharged home the following day unless unsuitable.

In cases of abdominal hysterectomy, the procedure was performed through a pfannenstiel incision. The bowel was packed off and then a three or four pedicle traditional clamp hysterectomy, completed. The vault was closed with a continuous absorbable suture and the abdomen, closed in layers. A urethral catheter was inserted at the onset of the procedure and removed the next day. Patients were discharged on the third or fourth postoperative day unless unsuitable.

Vaginal hysterectomy was performed by infiltration of the cervix with local anaesthetic and adrenaline, and then circumcised. The vaginal skin was retracted and ascending pedicles taken along the uterus until the tubo-ovarian pedicles were divided. The ovaries were always retained at vaginal hysterectomy. The vagina was closed with absorbable suture, and a vaginal pack and urethral catheter was inserted. Both were removed the following day and patients were discharged on the third or fourth postoperative day unless unsuitable.

In all types of hysterectomy, patients were discharged when pain-free (with or without oral analgesics), when urinary catheter had been removed and the woman was fully mobile and confident to self care at home.

\section{Findings}

In the 5-year period, a total of 202 hysterectomies were recorded on the hospital database under the care of one author. Detailed review of the notes confirmed that 12 were patients actually under the care of other consultants, 11 patients had not in fact had a hysterectomy performed and two sets of notes were untraceable. In three cases, patients under the care of the named consultant underwent TLH by a locum consultant and these cases have been excluded. One patient transferred care to another consultant to expedite surgery. Thus, 173 patients had undergone a hysterectomy under the care of the named consultant, and notes were available for review. Of the 173 cases, 18 TAHs, $17 \mathrm{VHs}$ and 138 TLHs were undertaken (Table 1).

\section{Total abdominal hysterectomy}

Eighteen TAHs were performed. All occurred in the first 2 years, with nine in each year except for one TAH which was performed in year 5 by another consultant. The one patient who had a TAH performed in year 5 by another consultant had opted for TAH instead of TLH to shorten her waiting time; this was a waiting list management issue, not a clinical decision. Nine patients were operated on by a doctor not trained to perform TLH and in the absence of the
Table 1 Number and percentage of total abdominal, vaginal and total laparoscopic hysterectomies performed each consecutive year of the study

\begin{tabular}{lcccc}
\hline Year & TAH; $n(\%)$ & VH; $n(\%)$ & TLH; $n(\%)$ & $\begin{array}{l}\text { Total } \\
\text { Hysterectomies }\end{array}$ \\
\hline 1 & $9(27.3)$ & $7(21.2)$ & $17^{\mathrm{a}}(51.5)$ & 33 \\
2 & $9(23.1)$ & $8(20.5)$ & $22^{\mathrm{a}}(56.4)$ & 39 \\
3 & 0 & $2(6.1)$ & $31(93.9)$ & 33 \\
4 & 0 & 0 & $39^{\mathrm{a}}(97.4)$ & 39 \\
5 & $0^{\mathrm{b}}$ & 0 & $29(96.7)$ & 29 \\
Total & $18(10.4)$ & $17(9.8)$ & $138(79.8)$ & 173 \\
\hline
\end{tabular}

${ }^{\text {a }}$ Single conversion occurred

${ }^{\mathrm{b}}$ One patient transferred care to another consultant for TAH to expedite surgery

named consultant. Ten patients had a TAH by the named consultant, of whom eight had been listed for this procedure by the named consultant and two patients had been listed for TAH by junior doctors. The indication for TAH was a large fibroid uterus (larger than 16 weeks gestation equivalent) in nine cases and three previous Caesarean sections in one case. At histology, the uterine size of these 10 cases performed over the 2 years by the consultant varied from 135 to $2,793 \mathrm{~g}$, median weight (no weight recorded in three of these specimens). See Fig. 1 for comparison of uterine size and hysterectomy type by consecutive years of experience.

\section{Vaginal hysterectomy}

Seventeen patients underwent vaginal hysterectomy. All operations occurred in the first 3 years; none in the last 2 years. Eight patients underwent vaginal hysterectomy by the named consultant, for uterine prolapse; three had procidentia and five had a cervix at, or below, the introitus. Four

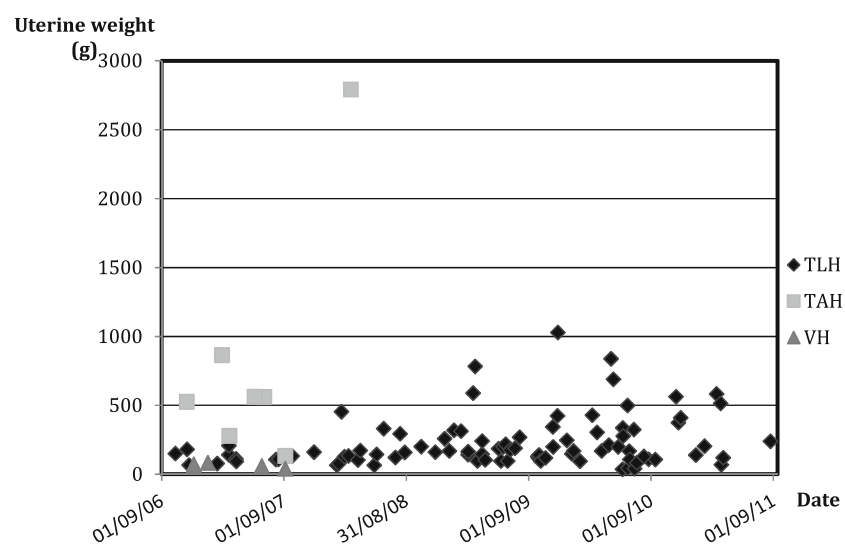

Fig. 1 For each route of hysterectomy, the weight of each individual uterus (where reported at histology) is plotted against the date surgery was performed 
of these eight patients had additional vaginal wall surgery. Seven of these patients had been listed by the author and one listed by a junior doctor. The remaining nine patients were all listed, and operated on, by a specialty doctor in the absence of the consultant; seven of these also had a vaginal repair.

\section{Total laparoscopic hysterectomy}

TLH was undertaken in 138 patients; 99 patients had been listed for surgery by the named consultant and 39 by other doctors on behalf of the named consultant. In two cases, a subtotal hysterectomy was performed as the patients had requested that their cervix be retained. There were three conversions to laparotomy for the following reasons:

1. Case 13 (year 1) had a completed TLH, but the abdomen was opened by a colorectal surgeon to repair injury to adherent bowel, which had occurred during the TLH.

2. Case 30 (year 2) was unable to be ventilated in a sufficiently head down position to allow adequate view of large fibroid uterus.

3. In case 85 (year 4), the uterus was so large that it filled the pelvis completely, leaving limited access to uterine vessels at source and a surgical assistant inexperienced in advanced laparoscopic surgery.

A laparoscopic morcellator was purchased in year 2, and one case required morcellation in year 2, five cases in year 3 , eleven cases in year 4 and five in year 5 . The median uterine weights in TLH cases increased in consecutive years from $110 \mathrm{~g}$ in year1 to $240 \mathrm{~g}$ in year 5 (Table 2).

\section{Complications}

There was one surgical complication in the TAH group; a patient who was operated on by a specialty doctor sustained

Table 2 The range and median uterine weight in grams for vaginal, abdominal and laparoscopic hysterectomy is shown for each year

\begin{tabular}{llrrr}
\hline & & \multicolumn{1}{l}{ VH } & \multicolumn{1}{l}{ TAH } & \multicolumn{1}{l}{ TLH } \\
\hline Year 1 & Range & $61-85$ & $280-866$ & $58-209$ \\
& Median & 67.5 & 561 & 110 \\
Year 2 & Range & 42 & $134-2,793$ & $67-455$ \\
& Median & 42 & 1,464 & 135 \\
Year 3 & Range & & & $97-784$ \\
& Median & & & 188.8 \\
Year 4 & Range & & & $37-1,030$ \\
& Median & & & 170 \\
Year 5 & Range & & & $70-584$ \\
& Median & & & 240 \\
\hline
\end{tabular}

Data obtained from the uterine weight documented at histology a bladder injury, which was repaired without event. There were no recorded surgical complications in the VH group. In the TLH group, there were 10 surgical complications; four bladder injuries, one bowel injury, two ureteric injuries, two acute haemorrhages and one significant postoperative bleed. Only one complication required immediate conversion to laparotomy as described above (case 13). Two patients were returned to theatre for intra-abdominal bleeding in the immediate postoperative period, one of which was managed by laparotomy by another consultant and the other managed laparoscopically by the author. One complication (ureteric injury) involved return to theatre for reimplantation of ureter and stent insertion. Details of the complications at TLH are shown in Table 3. The overall rate of surgical complication was $0 \%$ for $\mathrm{VH}, 5.6 \%$ for TAH and $7.2 \%$ for TLH. In the TLH group, there were two complications in the first year $(11.8 \%)$, three in the second $(13.6 \%)$, one in the third $(3.2 \%)$, one in the fourth $(2.6 \%)$ and three in the fifth (10.3\%).

\section{Conclusions}

This study demonstrates the outcome of offering a TLH to every patient in a general gynaecology clinic that is suitable for an abdominal hysterectomy. It is fundamentally different from many published studies, which examine the outcome of laparoscopic hysterectomy, where the procedure is only performed on selected cases. In this study, the outcomes of all hysterectomy patients are reported so this is a complete data set without selection bias. The study is unique in that the decision to offer all abdominal hysterectomy patients a TLH was made prospectively and then the outcome was studied.

The data show that the success of achieving a TLH increased with time; as cases were unselected, this increase is likely to be due to increase in surgical expertise. Over the whole study, excluding cases where other clinicians chose the surgical route ( 2 cases), performed the surgery ( 9 cases) or the patient had a VH (17 cases), $95 \%$ (138/145) of all cases offered a TLH had a TLH. The results show that TLH can justifiably be offered to all patients undergoing nonvaginal hysterectomy as the default procedure providing the surgeon is appropriately experienced in the technique.

Our intraoperative conversion rate to laparotomy was $2.2 \%$. Both uterine weight and adhesions have been shown as risk factors for conversion of TLH to laparotomy [16]. However, of the three conversions in this study, one was for anaesthetic reasons and one was for surgical assistant shortcomings. The single remaining conversion was for an enlarged uterus fixed in the pelvis and was compounded by an in experienced surgical assistant. It was considered safer to convert than risk a complication. In our current practice, this 
Table 3 Details of complications during total laparoscopic hysterectomy, shown by chronological case number

\begin{tabular}{|c|c|c|c|c|c|c|c|}
\hline $\begin{array}{l}\text { Patient } \\
\text { number }\end{array}$ & Year & Complication & Result & Conversion & Complicating factors & $\begin{array}{l}\text { Uterine } \\
\text { dimension } \\
\left(\mathrm{cm}^{3}\right)\end{array}$ & $\begin{array}{l}\text { Uterine weight } \\
(\mathrm{g})\end{array}$ \\
\hline 3 & 1 & Bladder injury & Repaired & No & Endometriosis. $2 \times$ LSCS & 235 & 151 \\
\hline 13 & 1 & Bowel injury & Repaired & Yes & Severe adhesions & 135 & Not recorded \\
\hline 31 & 2 & Ureteric injury & $\begin{array}{l}\text { Return to theatre. Reimplantation } \\
\text { of right ureter and stent } \\
\text { insertion }\end{array}$ & $\begin{array}{l}\text { No. Not } \\
\text { identified at } \\
\text { surgery }\end{array}$ & $\begin{array}{l}\text { Enlarged uterus with } \\
\text { adenomyosis }\end{array}$ & 504 & Not recorded \\
\hline 32 & 2 & Ureteric injury & $\begin{array}{l}\text { Repaired laparoscopically during } \\
\text { procedure }\end{array}$ & No & $\begin{array}{l}\text { Endometriosis of both side } \\
\text { walls. Dense adhesions } \\
\text { (unplanned opening of ureter) }\end{array}$ & 95 & 128 \\
\hline 38 & 2 & Bladder injury & $\begin{array}{l}\text { Repaired. Prophylactic right } \\
\text { ureteric stent }\end{array}$ & No & Deep infiltrating endometriosis & 189 & 145 \\
\hline 57 & 3 & Bladder injury & Repaired & No & Previous TVT & Not recorded & 590 \\
\hline 96 & 4 & Bladder injury & Repaired & No & $2 \times \operatorname{LSCS}$ & 400 & Not recorded \\
\hline 117 & 5 & Bleeding & $\begin{array}{l}\text { Return to theatre. Laparotomy. } \\
\text { Right uterine artery pedicle. } \\
\text { EBL } 1000 \mathrm{ml} \text {. }\end{array}$ & $\begin{array}{l}\text { No. Not } \\
\text { identified at } \\
\text { surgery }\end{array}$ & $\begin{array}{l}\text { Multiple adhesions between } \\
\text { bowel, ovary and uterus. } \\
\text { Previous pelvic sepsis }\end{array}$ & 144 & 130 \\
\hline 124 & 5 & $\begin{array}{l}\text { Infection/ } \\
\text { Bleeding }\end{array}$ & $\begin{array}{l}\text { Raw area of vault sutured } \\
\text { in theatre at } 3 / 52\end{array}$ & No & $\begin{array}{l}18 / 40 \text { fibroid uterus. Infection/ } \\
\text { bleeding at } 3 / 52 \text { post operation }\end{array}$ & Morcellated & 564 \\
\hline 126 & 5 & Bleeding & $\begin{array}{l}\text { Return to theatre. Right } \\
\text { uterine artery pedicle sutured } \\
\text { laparoscopically. EBL } 2500 \mathrm{ml}\end{array}$ & No & $\begin{array}{l}16 / 40 \text { fibroid uterus. } 7 \mathrm{~cm} \text { right } \\
\text { broad ligament fibroid adjacent } \\
\text { to cervix. Patient on warfarin }\end{array}$ & Not recorded & 375 \\
\hline
\end{tabular}

Uterine dimension was calculated using the height $(\mathrm{cm}) \times$ width $(\mathrm{cm}) \times$ depth $(\mathrm{cm})$ documented at histology to produce a modeled uterine volume in $\mathrm{cm}^{3}$

case would have been offered gonadotrophin releasing hormone agonists preoperatively to reduce the uterine size so that isolation of the uterine arteries could be undertaken as the first surgical step and the appropriate assistance would have been scheduled.

We consider that grossly enlarged uteri or a uterus that is wedged against the pelvic side-wall are likely to be the only remaining surgical reasons for conversion. However, even in these cases, an experienced surgical team with the correct equipment could be expected to achieve TLH in most cases. This is reflected in our data, as only one conversion occurred after the first 50 procedures even though median weight of uteri increased each year.

The primary indication for surgery in all the vaginal hysterectomy cases was uterine prolapse, and the majority of these patients had additional pelvic floor surgery performed. Uterine suspension procedures are now recognised treatment options for women with uterine prolapse [17], and the decline in vaginal hysterectomy with time in this study is explained by the introduction of laparoscopic sacrohysteropexy into the authors practice.

The overall perioperative complication rate for TLH was $7.2 \%$. Previous studies have shown complication rates of $7.1 \%$ [18] and $5.8 \%$ [19]. Six of the 10 complications occurred in high-risk patients with complicating factors including deep infiltrating endometriosis, previous multiple caesarean section and previous history of pelvic sepsis. This finding demonstrates that if all cases are offered TLH, including those with surgical comorbidity, the rate of complications is likely to be higher than where the procedure is only offered selectively.

Two complications were cases that were returned to theatre to control postoperative bleeding. In one case, a laparotomy was performed on return to theatre by another consultant where no active bleeding was identified but raw areas in the vault were over-sewn. In this case, it is questionable whether repeat surgery was justified. In the second case, the right uterine artery pedicle was sutured laparoscopically and laparotomy was not required. In the latter case, postoperative bleeding was caused by a uterine artery suture being dislodged when the large, part morcellated, uterus was delivered through the vault. This complication may have been prevented by morcellation to a small residual uterus that could be removed through the vault less traumatically. As surgical experience grows, complications are likely to reduce; however, conversely, it is also likely that more complex cases will be undertaken laparoscopically, which will increase the risk of complication. Thus, predicting how the complication rate should change each consecutive year, when more complex surgery is being undertaken on patients that would have previously been deemed unsuitable for laparoscopic approach is challenging.

Studies have previously shown that even during the learning curve, TLH is safe [20]. With increasing surgical experience, operation length and complication rate are expected to decrease [20]. In a review of 250 laparoscopic 
hysterectomies, complication rates decreased with time and increasing experience and compared favorably to those expected with open surgery [18]. Identification of procedure numbers needed for complication rates and operating time to plateau in an experienced laparoscopic surgeon have previously been defined as 10 procedures [14]; however, patients were selected for TLH based on a combination of factors including preoperative estimation of uterine size and therefore this is not an assessment of the learning curve in an unselected population.

Similarly, previous studies have described the learning curve with reference to shortening operating time [14]. In this study, where all cases were offered TLH including complex laparoscopic hysterectomy (cases with deep infiltrating endometriosis, adhesions, large uterus or multiple previous operations), comparing the length of operation at the beginning of the study, and in the earlier stage of the learning curve, with the length of the operation at a later stage makes an inaccurate measure, so these data have not been studied.

TLH is associated with shorter length of hospital stay and more rapid recovery $[3,6,7]$. Patient preference and expectation will play an important role in selecting most appropriate route of surgery, and our patients requested the operation that had the shortest recovery time. This is consistent with the evidence that women scheduled for a hysterectomy prefer laparoscopic hysterectomy compared to TAH [21]. We have made no attempt to collect long-term outcome; however, previous authors have reported improved quality of life outcomes at 4 years with laparoscopic hysterectomy compared with abdominal hysterectomy [22]. Women in this study were fully counseled about the risks and benefits of undertaking each route of hysterectomy. All women in this study, who were deemed suitable for TLH, opted for TLH, with the exception of one woman in year 5, who chose a TAH simply to expedite her admission.

A comparison of hospital and indirect costs associated with route of hysterectomy has showed that laparoscopicassisted vaginal hysterectomy had lower cost to employers on the basis of lost work hours compared with abdominal and vaginal hysterectomy [23]. Further research is needed to establish the true cost of laparoscopic hysterectomy compared to abdominal and vaginal hysterectomy; costs must be compared for the whole patient journey from primary admission until full return to normal activities.

TLH is associated with a low rate of complication and a low conversion rate to laparotomy if performed by an experienced surgeon with the appropriate assistance and equipment. In benign gynaecology, total laparoscopic hysterectomy offers considerable advantages over traditional abdominal hysterectomy and should be offered as the default surgical approach when vaginal hysterectomy is not possible.
Conflict of interest The authors report no conflicts of interest. The authors alone are responsible for the content and writing of the paper.

\section{References}

1. Reich H, Decaprio J, McGlynn F (1989) Laparoscopic hysterectomy. J Gynecol Surg 5:213-216

2. Gendy R, Walsh CA, Walsh SR, Karantanis E (2011) Vaginal hysterectomy versus total laparoscopic hysterectomy for benign disease: a meta-analysis of randomized controlled trials. Am J Obstet Gynecol 204(5):388

3. Olsson JH, Ellstrom M, Hahlin M (1996) A randomised prospective trial comparing laparoscopic and abdominal hysterectomy. $\mathrm{Br}$ J Obstet Gynaecol 103:345-350

4. National Institute for Health and Clinical Excellence (2010) Laparoscopic hysterectomy (including laparoscopic total hysterectomy and laparoscopically assisted vaginal hysterectomy) for endometrial cancer. IPG356. London: National Institute for Health and Clinical Excellence

5. National Institute for Health and Clinical Excellence (2007) Laparoscopic techniques for hysterectomy. IPG239. London: National Institute for Health and Clinical Excellence

6. Garry R, Fountain J, Mason S, Napp V, Brown J, Hawe J et al (2004) The eVALuate study: two parallel randomised trials, one comparing laparoscopic with abdominal hysterectomy, the other comparing laparoscopic with vaginal hysterectomy. BMJ. doi:10.1136/bmj.37984.623889.F6

7. Jacoby VL, Autry A, Jacobson G, Domush R, Nakagawa S, Jacoby A (2009) Nationwide use of laparoscopic hysterectomy compared with abdominal and vaginal approaches. Obstet Gynecol 114(5):1041-1048

8. Falcone T, Walters MD (2008) Hysterectomy for benign disease. Obstet Gynecol 1(3):753-767

9. Sculpher M, Manca A, Abbott J, Fountain J, Mason S, Garry R (2004) Cost effectiveness analysis of laparoscopic hysterectomy compared with standard hysterectomy: results from a randomised trial. BMJ. doi:10.1136/bmj.37942.601331.EE

10. Bijen CBM, Vermeulen KM, Mourits MJE, de Bock GH (2009) Costs and effects of abdominal versus laparoscopic hysterectomy: systematic review of controlled trials. PLoS One 4(10):e7340. doi:10.1371/journal.pone.0007340

11. Barnett JC, Judd JP, Wu JM, Scales CD, Myers ER, Havrilesky LJ (2010) Cost comparison among robotic, laparoscopic, and open hysterectomy for endometrial cancer. Obstet Gynecol 116(3):685-693

12. Nieboer TE, Spaanderman ME, Bongers MY, Vierhout ME, Kluivers KB (2010) Gynaecologists estimate and experience laparoscopic hysterectomy as more difficult compared with abdominal hysterectomy. Gynecol Surg 7:359-363

13. Ballantyne GH (2002) The pitfalls of laparoscopic surgery: challenges for robotics and telerobotic surgery. Surg Laparosc Endosc Percutan Tech 12(1):1-5

14. Rosen DMB, Cario GM, Carlton MA, Lam AM, Chapman M (1998) An assessment of the learning curve for laparoscopic and total laparoscopic hysterectomy. Gynaecol Endosc 7 (6):289-293

15. Perino A, Cucinella G, Venezia R, Castelli A, Cittadini E (1999) Total laparoscopic hysterectomy versus total abdominal hsterectomy: an assessment of the learning curve in a prospective randomized study. Hum Reprod 14(12):2996-2999

16. Park SH, Cho HY, Kim HB (2011) Factors determining conversion to laparotomy in patients undergoing total laparoscopic hysterectomy. Gynecol Obstet Invest 71(3):193-197

17. National Institute for Health and Clinical Excellence (2009) Insertion of mesh uterine suspension sling (including 
sacrohysteropexy) for uterine prolapse repair. IPG282. London: National Institute for Health and Clinical Excellence

18. Jones RA (1995) Complications of laparoscopic hysterectomy. Gynaecol Endosc 4(2):95-99

19. Liu CY, Reich H (1994) Complications of total laparoscopic hysterectomy in 518 cases. Gynecol Endosc 3:203-208

20. Vaisbuch E, Goldchmit C, Ofer D, Agmon A, Hagay Z (2006) Laparoscopic hysterectomy versus total abdominal hysterectomy: a comparative study. Eur J Obstet Gynecol Reprod Biol 126 (2):234-238
21. Kluivers KB, Opmeer BC, Geomini PM, Bongers MY, Vierhout ME, Bremer GL et al (2009) Women's preference for laparoscopic or abdominal hysterectomy. Gynecol Surg 6(3):223-228

22. Nieboer TE, Hendriks JC, Bongers MY, Vierhout ME, Kluivers KB (2012) Quality of life after laparoscopic and abdominal hysterectomy: a randomized controlled trial. Obstet Gynecol 119(1):85-91

23. Lenihan JP Jr, Kovanda C, Cammarano C (2004) Comparison of laparoscopic-assisted vaginal hysterectomy with traditional hysterectomy for cost-effectiveness to employers. Am J Obstet Gynecol 190(6):1714 